The $B D J$ News section accepts items that include general news, latest research and diary events that interest our readers. Press releases or articles may be edited, and should include a colour photograph if possible. Please direct your correspondence to the News Editor, Arveen Bajaj at the BDJ, The Macmillan Building, 4 Crinan Street, London N19XW or by email to bdj@bda.org

\section{Dentists gain incorporation status}

Dentists can now own their own companies for the first time in fifty years due to new regulations which came into force on the 31 July. After four years of lobbying, section 42 of the 1984 Dentist Act is to be removed and dentists can have incorporation status. They will be able to set up as a limited company or as a limited liability partnership (LLP).

Dentists will be able to limit liabilities, have shareholders (including their spouse or staff), raise capital from outside to purchase new premises or dental equipment and keep ownership of the business separate from the management. Incorporation will mean protection of personal assets and the option to bring other dental professionals into practice management. Future retirement planning may be easier and practices will be allowed to grow substantially.

If they become a limited company, the current professional indemnity cover they have will no longer be valid and professional indemnity cover for the new company will need to be arranged.

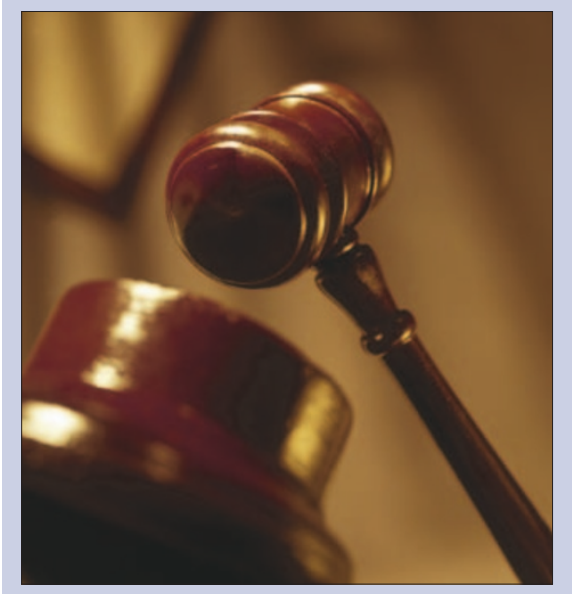

\section{Double dental prize success}

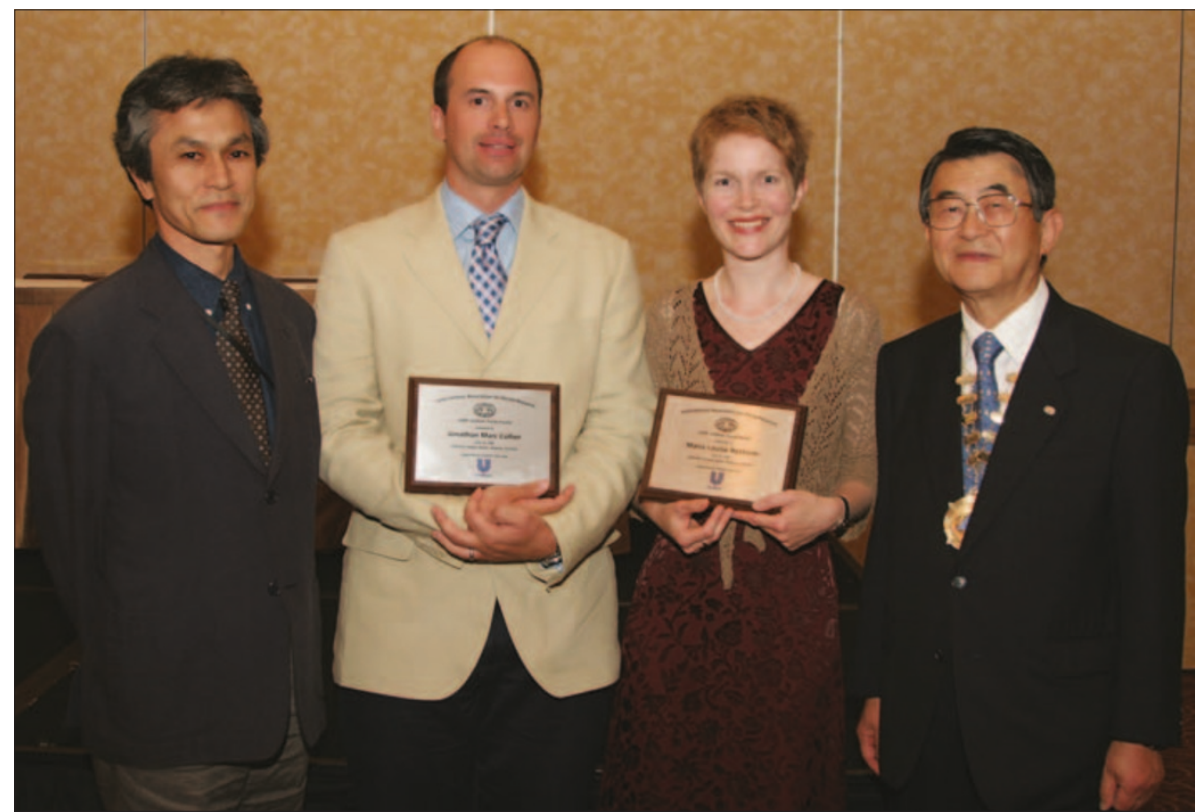

Two researchers from Barts and The London, Queen Mary's School of Medicine and Dentistry have won the International Association for Dental Research's (IADR) Hatton Prize.

Dr Maria Nystrom of the Institute of Cancer won the senior prize for her $\mathrm{PhD}$ research into oral cancer. Her group showed that non-steroidal anti-inflammatory drugs (NSAIDs) block invasion of oral cancer cells by inhibiting the function of an important 'cell adhesion molecule', the $\alpha v \beta 6$ integrin, which is over expressed in oral cancer. The junior prize was won by Dr Jonathan Collier of the Institute of Cell and Molecular Science for research also into oral cancer. It looked at the expression of chemokine receptors on the surface of oral cancer cells.

The IADR seeks to advance research and increase knowledge for the improvement of oral health worldwide. Its annual Hatton Prize is sponsored by Unilever and the awards were presented during the IADR's 84th General Session in Brisbane, Australia, at the end of June, 2006. Pictured left to right, Yoshiro Takano, Hatton committee chairman, Dr Jonathan Collier, Dr Maria Nystrom and Takayuki Kuroda, President, IADR.

\section{Race for charity}

Andy Parry, a dentist from Integrated Dental Holdings in Oswaldtwistle, recently raised almost $£ 3,000$ on completion of the London Marathon earlier this year.

Andy, a 54-year-old diabetic raised the cash for two key charities, The Royal Air Force Benevolent Fund and Derian House Childrens Hospice.

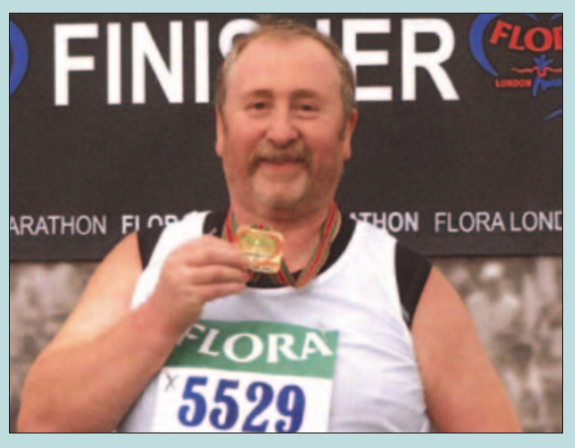




\section{DIARY}

September

Moving to private practice

Venue: The Midland Hotel, Manchester

Date: 8 September 2006

www.bda-events.org

The British Society of Paediatric Dentistry

Annual Scientific Conference

'The Art \& the Science'

Venue: The Hilton, Leeds City

Date: 12-15 September 2006

www.bspd.co.uk/conf-2006.html

European Society for Oral Laser Applications/

Hellenic Society for Oral Laser Applications

1st Mediterranean Laser Congress

Venue: Hilton Hotel Rhodes Resort, Greece

Date: 21-23 September 2006

Email: esola2006@medacad.org

www.esola.at

FDI Annual World Dental Congress

Venue: Shenzhen, China

Date: 22-25 September 2006

Email: congress@fdiworldental.org

www.fdiworldental.org

October

Preparing for retirement

Venue: Cedar Court Hotel, Harrogate

Date: 6 October 2006

www.bda-events.org

Community Dental Services Group Annual

Presidential and Scientific meeting

Venue: Marriott Forest of Arden Hotel,

Birmingham

Date: 12-13 October 2006

www.bda-events.org

The American Dental Association (ADA)

147th ADA Annual Scientific Session and

Marketplace Exhibition

Venue: Mandalay Bay Resort and

Convention Center, Las Vegas

Date: 16-19 October 2006

www.ada.org

Hospitals Group Annual Presidential and Scientific meeting

Venue: Portmeirion, North Wales

Date: 26-27 October 2006

www.bda-events.or

November

British Academy of Cosmetic Dentistry's

(BACD) 2nd Annual Conference

Venue: Britannia International Hotel, London

Date: 16-17-18 November 2006

Email: info@bacd.com

www.bacd.com

\section{New statutory register opens for dental nurses and dental technicians}

Last month saw the opening of a new statutory register for dental care professionals (DCPs) practising in the UK. Dentists, dental hygienists and dental therapists are already registered with the GDC and now, other professionals who play a role in patients' dental care, including dental nurses and dental technicians, will join the GDC's registers. Registration means that dental professionals have met educational standards and that they are professionally accountable for their actions.

A survey conducted by the GDC found that 55\% of adults in the UK believe that dental nurses currently need to be registered with a regulatory body before they can practise. On being told that dental nurses did not need to be registered, twothirds $(67 \%)$ of adults thought that dental nurses should be.

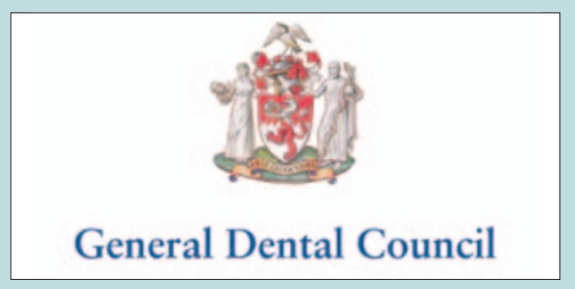

\section{Dental schools need more funding}

UK dental schools are providing sound training for the dentists of tomorrow, but many are in need of a major upgrade, according to a new report from the General Dental Council (GDC). Around 700 new dentists graduate from UK dental schools every year. This month, the GDC has published the General Report on its latest round of quality assurance visits to the schools. The report highlights the GDC's key findings and provides a snapshot of the current state of UK undergraduate dental education. It identifies examples of good educational practice at the UK's 13 dental schools and also makes recommendations for further developing the delivery of dental education.

A GDC inspection panel visited all 13 dental schools in the UK between October 2003 and July 2005. The panel's job was to check that GDC standards for training future dentists, as set out in its guidance document The First Five Years, are being implemented. The inspectors looked at the undergraduate dental programme and also the running of the final examination at each school. They met academic and clinical staff and dental students, and looked at the provision of clinical and educational facilities. The inspectors found that all UK dental schools are, on the whole, meeting the GDC's expectations of undergraduate dental education. The report emphasises and welcomes the high level of commitment evident amongst dental school staff, the opportunities outreach teaching is giving dental students to treat patients in a general practice setting, and the high quality student support systems in place at all schools.

However, the report also highlights some areas of serious concern. The inspectors warn that there is an urgent need for substantial additional funding if high quality dental training is to be sustained. In particular, they found that many dental teaching hospitals are in need of a major upgrade, and greater investment is needed in academic staffing to ensure there is a sufficient complement of teachers to deliver the training programmes. The GDC is calling on the Departments of Health, the higher education funding councils, NHS agencies, and others with a role in supporting dental education, to address these concerns as a matter of urgency.

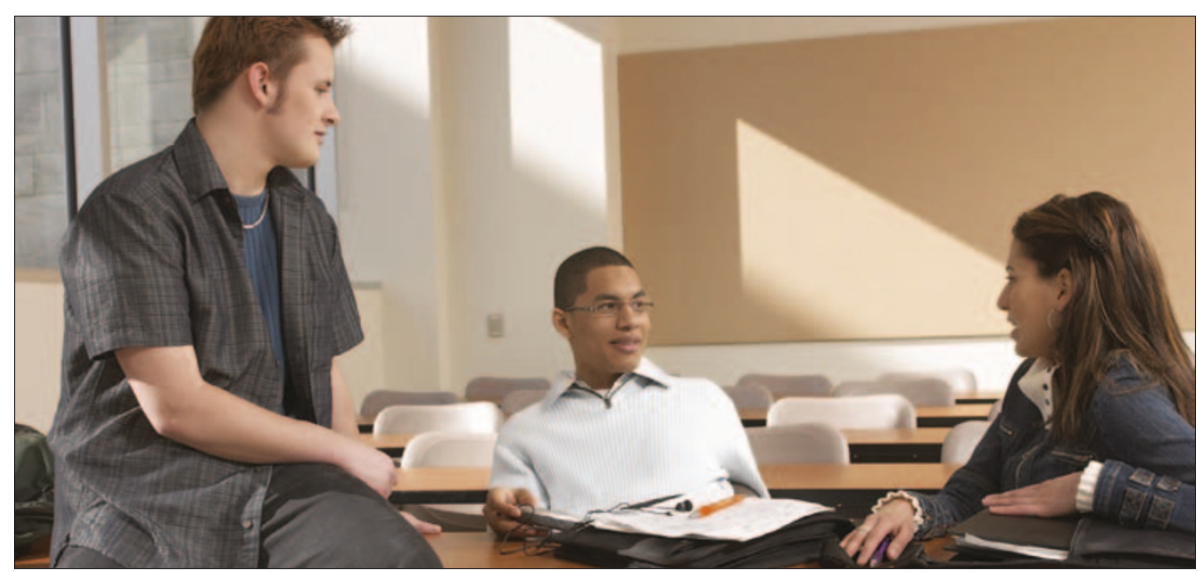




\section{Runners raise cash for kids}

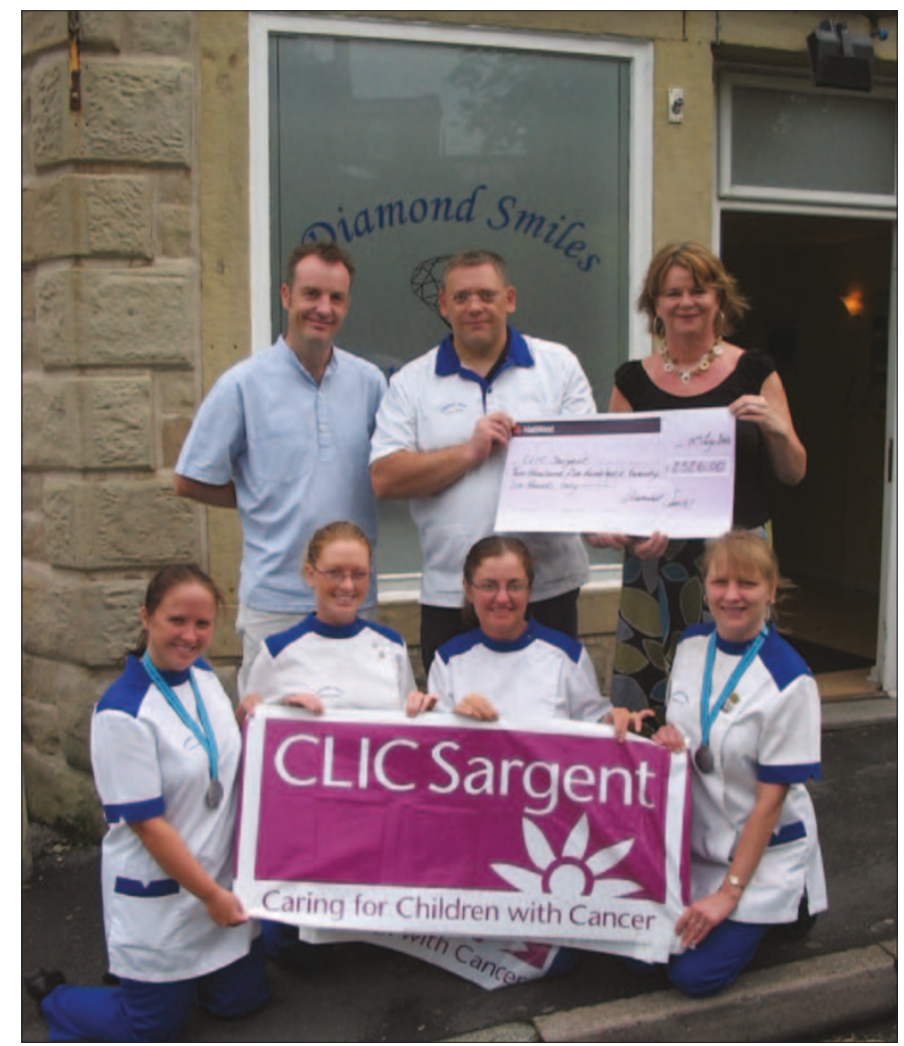

Diamond Smiles Dental Centre in Barnoldswick, East Lancashire, has raised $€ 2,526$ for CLIC Sargent, a charity for children living with cancer by running the Great Manchester Run on 21 May 2006. Practice owner Adam Evans, associate dentist Richard Parker, practice manager Michelle Hudson and dental nurses Donna Cooper, Julie Hayton and Alex Stobbs all took part. Pictured, the runners present their cheque to Helen Relihan from CLIC Sargent.

\section{Home oral hygiene works says study}

Researchers have found that gingival bleeding and halitosis were greatly reduced after a two-week oral hygiene programme of dental flossing and tooth brushing.

The list of excuses for not brushing or flossing is endless, but according to a new study published in the Journal of Periodontology, these are two tasks that should not be omitted from the daily hygiene routine.

In the study, fifty-one sets of twins between the ages of 12 and 21 years of age were examined for gingival bleeding and halitosis. Each set of twins was then divided into two groups. One group of twins manually brushed their teeth and tongue twice a day for two weeks. The second group of twins was given the same instructions in addition to using dental floss twice a day. After two weeks, the twins were examined again for gingival bleeding and halitosis.

Twins were examined in this study because each individual set shares the same environmental factors such as dietary habits, health and life practices, thereby constituting a perfect case-control matched study.

Researchers found that tongue and tooth brushing in combination with dental flossing significantly decreased gingival bleeding by 38\% after a twoweek oral hygiene programme. Halitosis was also reduced. In the group that did not floss as part of their daily routine, gingival bleeding sites increased by almost $4 \%$.

"Gingival bleeding and halitosis is often the first sign of poor oral hygiene that may eventually lead to further periodontal problems," said Walter A. Bretz, Department of Cariology and Comprehensive Care, New York University College of Dentistry. "A good way to prevent periodontal disease and tooth decay is through at-home oral hygiene care and routine dental visits."

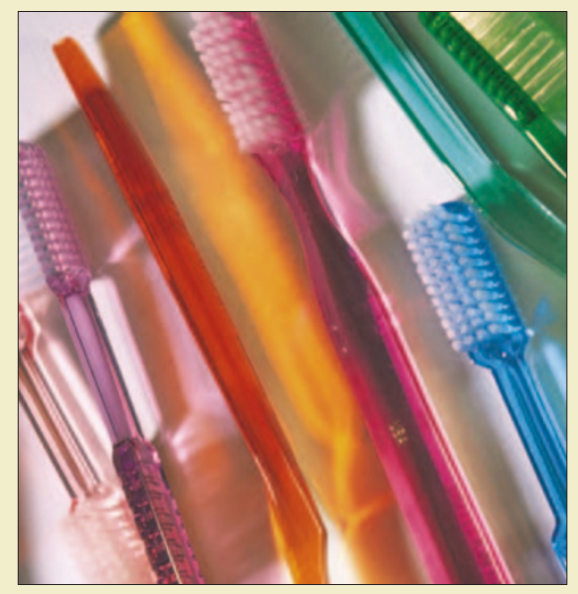




\section{Review on exam for overseas dentists}

The International Qualifying Examination (IQE) may be replaced with a new streamlined exam, according to the General Dental Council (GDC). It is calling for views on its proposal for a new exam to assess the competence of dentists from outside the European Economic Area (EEA) who wish to practise in the UK. The IQE has come under increasing strain due to the large influx of dentists from overseas and the limit on places dental schools, which host the exam.

At present, dentists from outside the EEA sit the IQE and those who pass can apply for registration to practise unsupervised on patients in the UK. After five years of the IQE, the GDC is carrying out a comprehensive review of how it assesses the competence of an overseas dentist for UK practice. The aim of the review is to ensure the GDC's processes are in step with developments in assessment techniques and that they are fulfilling their public protection purpose.

A review group is proposing that the current IQE is replaced with a new exam to assess the clinical skills and knowledge of overseas dentists. This streamlined exam would differ significantly from the IQE and would make use of modern assessment methods to ensure a robust and fair test for dentists. The exam will also be better able to cope with fluctuations in demand than

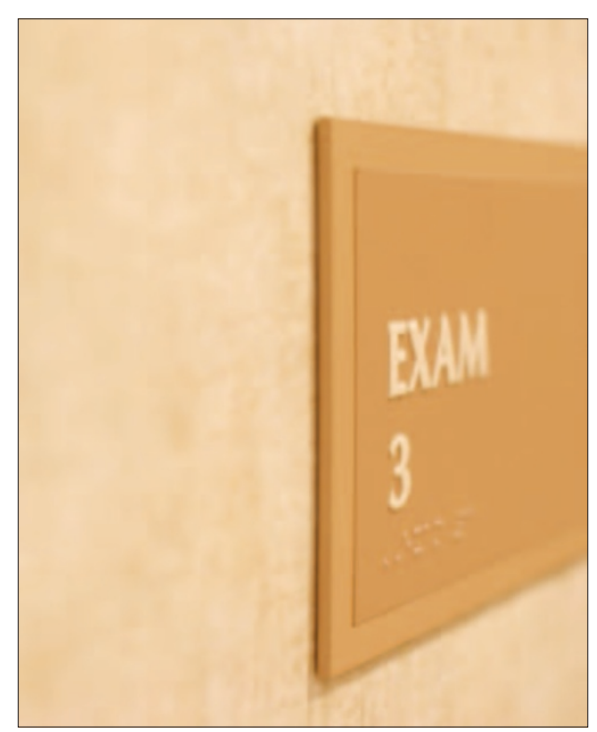

the current IQE, more practicable for the exam centres to hold and will keep waiting times for candidates to a minimum. Key differences from the current exam would be a two-part rather than a three-part exam, the introduction of an Objective Structured Clinical Examination (OSCE) and testing of candidates' technical skills in updated dental manikin exercises, not on real patients. The consultation document is available on the GDC website www.gdc-uk.org and the closing date for responses is Friday 6 0ctober 2006.

\section{Mouth cancer breakthrough}

Cancer Research UK scientists have discovered mouth cancer can develop along two distinct pathways, an aggressive or less aggressive route, reveals a study published in Cancer Research this month.

The research lays the foundations for further studies that could help to improve the management of pre-cancerous lesions and possibly prevent the development of the disease in the future.

The researchers from Cancer Research UK's Beatson Institute for Cancer Research in Glasgow took samples from the mouths of 19 people with pre-cancerous lesions, or spots, 16 patients with mouth cancer and four normal mouths. They compared these samples, each one made up from thousands of cells, in an attempt to find out if the disease develops in more than one way.

The researchers identified two different routes by which mouth cancer develops, resulting in 'mortal' and 'immortal' tumour cells when they are grown in the laboratory. 'Mortal' and 'immortal' cells are genetically very different. 'Mortal' cells have a limited lifespan and so will exhaust themselves as they develop into a tumour, being less likely to spread or recur following treatment. 'Immortal' cells on the other hand are much more resilient and will keep on dividing, making them more likely to spread and to cause a recurrence - a major characteristic of aggressive disease.

They found that faults in the p53 gene and missing expression of the p16 gene were closely associated with 'immortal', aggressive tumours. Importantly, these same changes were also found in precancerous cells, which grew in laboratory cultures as 'immortal' cells. When it is working normally, the p53 gene stops damaged cells dividing and should stop cancers growing, which is probably why faults were found in the p53 gene in 'immortal' cells rather than in 'mortal' ones. The p16 gene helps to control the cell regulation process and can prevent cancer from developing - expression of this was missing from most of the more aggressive mouth cancer cells.

\section{The beauty of the molecular world}

An image of an oral bacterium was amongst a number of stunning images honoured at the Wellcome Trust Biomedical Image Awards 2006. Other winning images included the blind spot of an eye, the stinging hairs on a nettle leaf and cancerous cells.

The image, Actinobacillus actinomycetemcomitans was captured by Derren Ready from the Eastman Dental Institute, London.

The winning images were selected from those submitted to the Medical Photographic Library over the past twelve months. This collection of over 160,000 images covers modern medicine and biomedical science, the history of medicine and the history of human culture from the earliest periods of civilization to the present day, reflecting the diversity of the interests of Sir Henry Wellcome.

Presenting the awards, scientist and broadcaster Kathy Sykes described the award winners as "a stunning collection of images that portray a range of surprises, intrigues, beauties and even horrors of biomedical science."

Other images recognised in the awards ceremony include human colon cancer cells, taken by Dave McCarthy and Annie Cavanagh from the University of London School of Pharmacy and squamous cell carcinoma, taken by Anne Weston from Cancer Research UK. The latter shows a cell from the second most common form of skin cancer, frozen and split open to reveal its nucleus, an aggressive, beast-like cell.

The award winning images are on display at the Wellcome Library, 210 Euston Rd, London, along with audio clips of the scientists behind the images discussing their work. Entrance to the exhibition is free. They can also be viewed online at www. wellcome.ac.uk/bia2006.

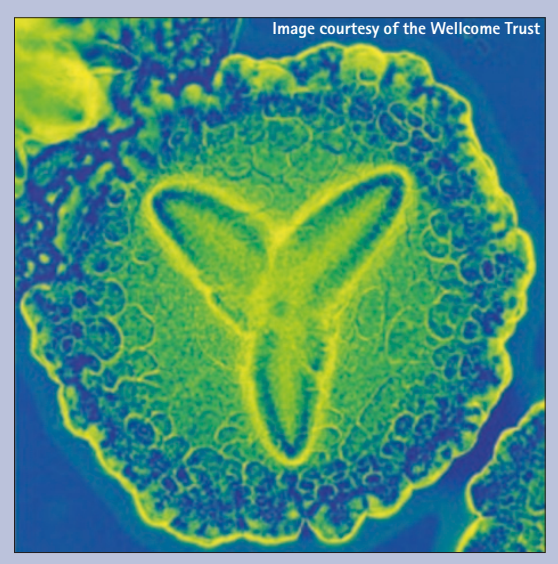

